\title{
INIBIDOR DE CORROSÃO OBTIDO POR LIXIVIAÇÃO DE CIGARRO APÓS SEU CONSUMO
}

\author{
M. G. PERAÇA ${ }^{1}$, L. M. M. MACHADO ${ }^{2}$ e L. M. RODRIGUES ${ }^{3}$ \\ 1,2,3 Universidade Federal do Pampa - Campus Bagé, RS - Curso de Engenharia Química \\ E-mail para contato: lauren_machado@hotmail.com
}

\begin{abstract}
RESUMO - O cigarro apresenta diferentes componentes químicos em sua composição. Após seu consumo, gera um resíduo sólido que sem o correto descarte, torna-se um poluente ao meio ambiente. A corrosão é um processo espontâneo de degradação de materiais, geralmente metálicos, ocasionando riscos de rupturas de estruturas, explosões ou contaminações. Como alternativa viável para o combate à corrosão surgem os inibidores naturais. O objetivo deste trabalho foi buscar um destino adequado aos resíduos de cigarros, após seu consumo, como inibidores de corrosão em aço carbono e Fe. A metodologia compreendeu a lixiviação aquo-solúvel dos filtros, medidas de $\mathrm{pH}$ das lixívias, exposição direta dos metais aos extratos, análise morfológica por microscopia óptica e experimentos eletroquímicos por potenciometria. Os resultados obtidos apresentaram o caráter inibidor dos extratos obtidos sobre o aço. Os componentes extraídos a partir da lixiviação de filtros amarelo, os quais ocorrem em cigarros com maiores teores de nicotina, representaram maior nível de proteção contra a corrosão, comparando-se com a lixívia de filtros branco. Isto evidencia a relevância deste estudo, tanto na questão ambiental, quanto na proteção de metais.
\end{abstract}

\section{INTRODUÇÃO}

O tabaco é originário das Américas e conhecido há cerca de oito mil anos por praticamente todas as culturas que habitavam o continente antes dos grandes descobrimentos luso-espanhóis. Cerca de 12,3 bilhões de "bitucas" são descartadas diariamente, sendo o seu tempo de decomposição de até cinco anos. Este resíduo contém muitas substâncias tóxicas, o que pode provocar a poluição de solos e águas. Algumas formas de reciclagem deste resíduo são adotadas em países desenvolvidos, sendo pouco difundido no Brasil (Penna, 2012).

Os resíduos de cigarro são alvo de pesquisas para o seu reaproveitamento, sendo utilizados em processos de hidrossemeadura (Tonon et al., 2012). O projeto Cigarette Waste Brigade transforma o filtro do resíduo do cigarro em plástico, extraindo o acetato de celulose (Carvalho, 2014). Em outro projeto, as substâncias extraídas dos filtros de resíduos de cigarros são utilizadas como anticorrosivos ao aço $\mathrm{J} 55$, em meio ácido, a $105^{\circ} \mathrm{C}$ e $30^{\circ} \mathrm{C}$, com eficiências de 61 e $99 \%$ (Vahidhabanu et al. 2014).

A corrosão é um processo resultante da ação química ou eletroquímica do meio sobre um material, podendo ainda estar aliada ou não a esforços mecânicos. O efeito da corrosão influencia a durabilidade e o desempenho dos materiais, podendo ocasionar graves acidentes e gastos diretos ou indiretos (Gentil, 2011). Os inibidores de corrosão podem ser substâncias 
puras (inorgânicas ou orgânicas) ou misturas. Tais substâncias promovem uma acentuada diminuição nos processos corrosivos (Brett e Brett, 1996).

O presente trabalho tem por objetivo investigar as substâncias aquo-solúveis presentes nos filtros branco e amarelo de cigarros, após seu consumo, como inibidor de corrosão do aço API 5L Grau B e Ferro Armco (comercialmente puro).

\section{MATERIAS E MÉTODOS}

\subsection{Materiais}

As amostras metálicas utilizadas foram aço API 5L Grau B e Fe comercial puro (Fe Armco). Os resíduos sólidos de cigarros após o consumo, filtros brancos e amarelos, são apresentados na Figura 1.

Figura 1 - Resíduos de cigarros, (a) filtros brancos e (b) filtros amarelos.
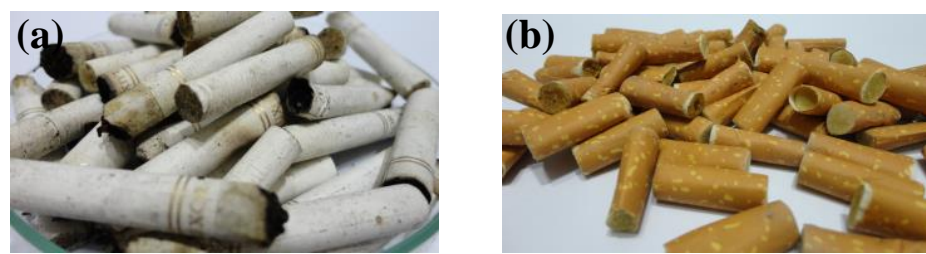

Fonte: As autoras, 2016.

Os equipamentos utilizados foram medidor digital de $\mathrm{pH}$, microscópio estereoscópico, multímetro, balança analítica, potenciostato Autolab. Nos testes eletroquímicos empregou-se célula eletroquímica a três eletrodos, com eletrodo de referência saturado de calomelano $\left(\mathrm{Hg} / \mathrm{Hg}_{2} \mathrm{Cl}_{2}\right)$, como contra eletrodo um fio de platina, e aço ou Fe como eletrodos de trabalho.

\subsection{Procedimento experimental}

A metodologia desenvolvida associa a coleta e preparo dos resíduos de cigarros, sendo manualmente removido o papel de rolamento dos filtros. As Figuras 2, 3 e 4 apresentam os procedimentos de lixiviação dos compostos aquo-solúveis, preparo das amostras metálicas e exposição das amostras nas soluções, respectivamente.

Figura 2 - Processo de lixiviação dos compostos aquo-solúveis dos filtros de cigarros.

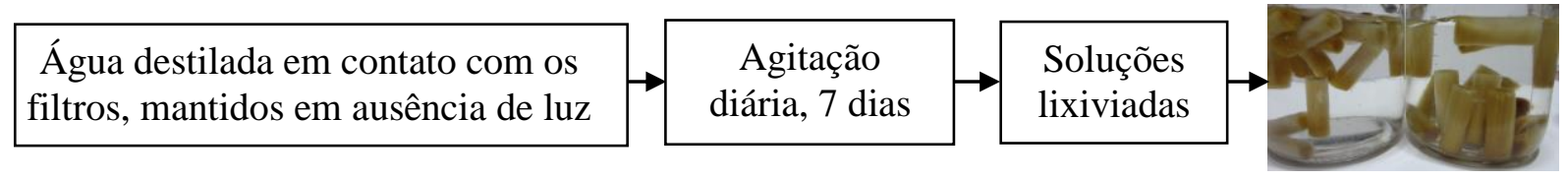

Figura 3 - Preparo das amostras metálicas.

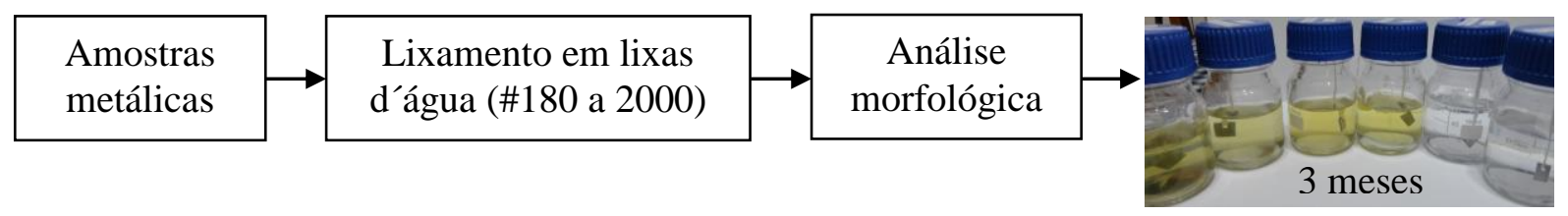




\section{Congresso Brasileiro de Engenharia Química em Iniciação Científica UFSCar - São Carlos - SP 16 a 19 de Julho de 2017}

Figura 4 - Exposição das amostras.

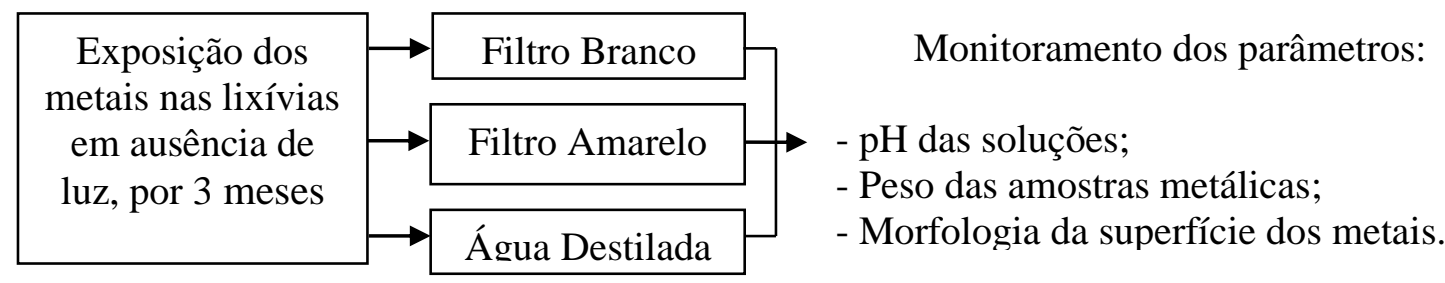

Foram realizados testes eletroquímicos para determinação de potencial e taxa de corrosão, e para o conhecimento do comportamento dos metais nas respectivas lixívias, por potenciometria. $\mathrm{O}$ método de voltametria cíclica foi aplicado a uma velocidade de varredura de $10 \mathrm{mV} . \mathrm{s}^{-1}$, no intervalo de potenciais $+172 \mathrm{a}+342 \mathrm{mV}$. Os resultados foram expressos em relação ao eletrodo normal de hidrogênio $(\mathrm{ENH})$ e obtidos na presença de oxigênio.

\section{RESULTADOS E DISCUSSÃO}

A morfologia das amostras metálicas foi observada por microscopia antes e após sua exposição nas lixívias. Na Figura 5 são apresentadas as amostras de aço e Fe preparadas por lixamento, antes da exposição às lixívias. Observam-se apenas as marcas relativas ao lixamento das amostras, com a ausência de defeitos ou ataques prévios aos metais.

Figura 5 - Morfologia das amostras metálicas anterior à exposição.

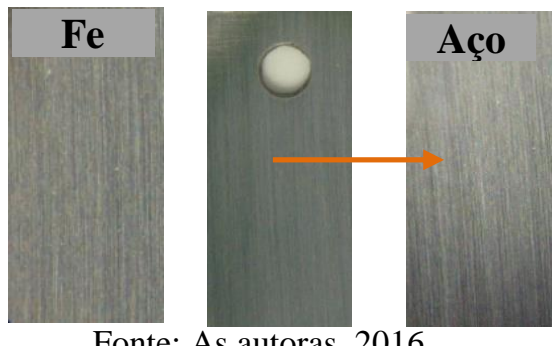

A morfologia dos resíduos sólidos dos filtros de cigarro após o seu consumo pode ser visualizada na Figura 6.

Figura 6 - Morfologia dos filtros de cigarros, (a) filtro branco e (b) filtro amarelo.

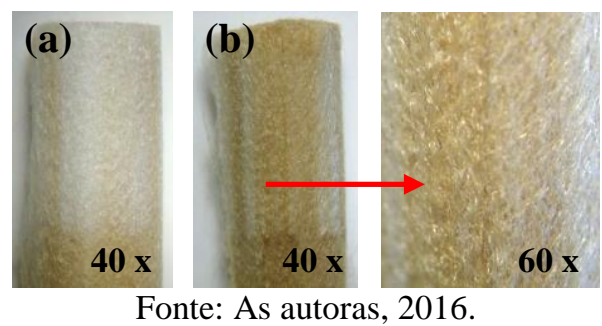

A caracterização dos extratos obtidos foi dado pelos valores de $\mathrm{pH}$, apresentados na Tabela 1, bem como, os valores para a água destilada, para comparação. 
Tabela 1 - Características do pH inicial e final dos extratos.

\begin{tabular}{|c|c|c|c|}
\hline Solução & $\mathrm{pH}$ inicial & $\mathrm{pH} 3$ meses Fe & $\mathrm{pH} 3$ meses Aço \\
\hline \hline Lixívia do filtro branco & 5,0 & 7,2 & 8,8 \\
\hline Lixívia do filtro amarelo & 5,2 & 4,0 & 4,8 \\
\hline Água destilada & 7,2 & 6,8 & 4,0 \\
\hline
\end{tabular}

Observou-se que em presença do $\mathrm{Fe}$ os valores de $\mathrm{pH}$ alteraram-se menos em comparação aos extratos contendo o aço. Em geral ocorreu uma acidificação do valor de $\mathrm{pH}$ da água destilada, praticamente a manutenção dos valores de $\mathrm{pH}$ na lixívia do filtro amarelo e o aumento de $\mathrm{pH}$ na solução extraída do filtro branco. A diminuição do valor de $\mathrm{pH}$ provavelmente tenha ocorrido pela grande quantidade de produtos de corrosão liberados na amostra de água, possivelmente óxidos de ferro, provenientes do ataque, no caso do aço. Os valores de $\mathrm{pH}$ quase inalterados, nos extratos do filtro amarelo, talvez sejam um indicativo do seu caráter inibidor da corrosão metálica. E a alcalinidade dos extratos de filtros brancos provavelmente ocorreu devido à natureza dos compostos formados na superfície do metal.

A Figura 7 apresenta a morfologia dos metais, observada por microscopia, após os 3 meses de exposição, e isentas dos produtos de corrosão acumulados: Em água, o Fe não sofreu ataque corrosivo, mas o aço apresentou ataque localizado, sob a forma de pites, na sua superfície. Destaca-se que os ataques localizados são a forma mais severa de corrosão metálica, podendo ocasionar a perfuração do material em pouco tempo (Gentil, 2011). Em extrato do filtro branco de cigarro, o Fe apresentou um leve ataque superficial, com a forma alveolar, enquanto o aço foi atacado de maneira uniforme na sua superfície. Em extrato do filtro amarelo de cigarro, observou-se um ataque superficial no Fe, com a forma transgranular, ao passo que o aço apresentou a sua forma de ataque mais superficial e leve, dentre as observadas para todos os meios de exposição.

Figura 7 - Morfologia do ataque ao metal após remoção dos produtos de corrosão
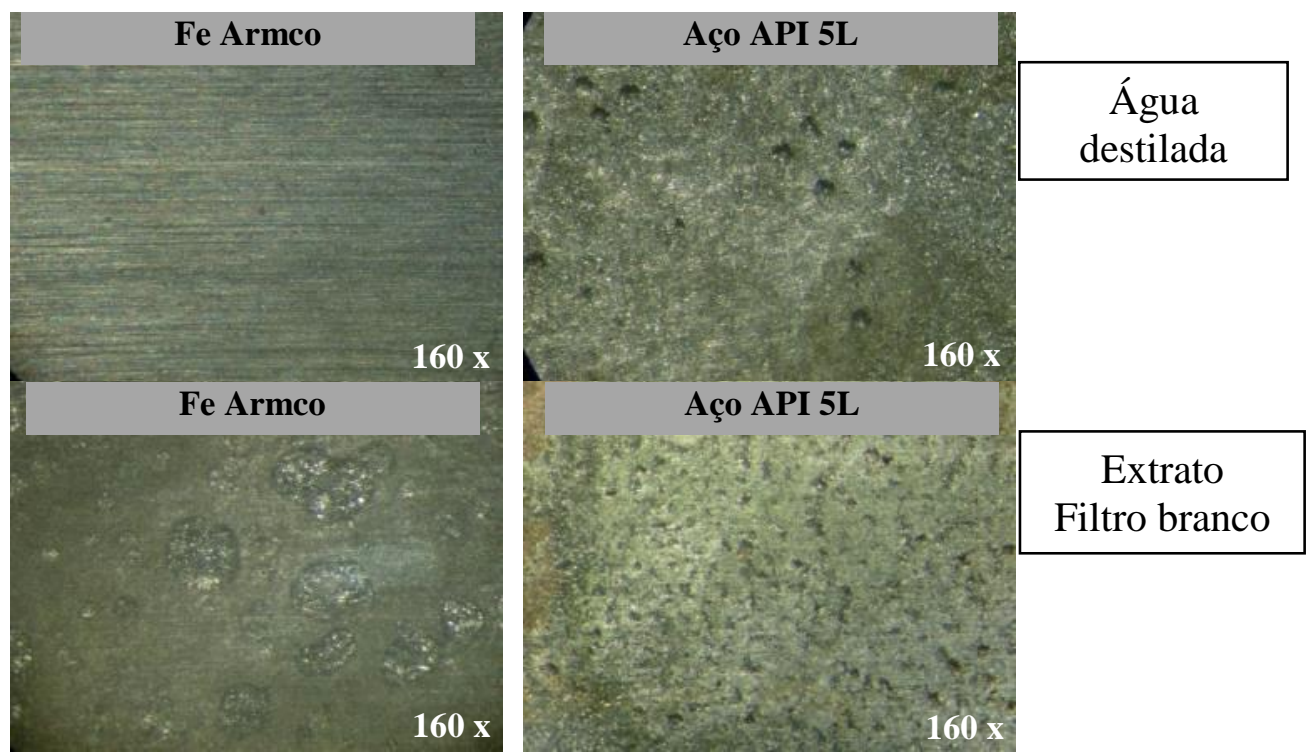


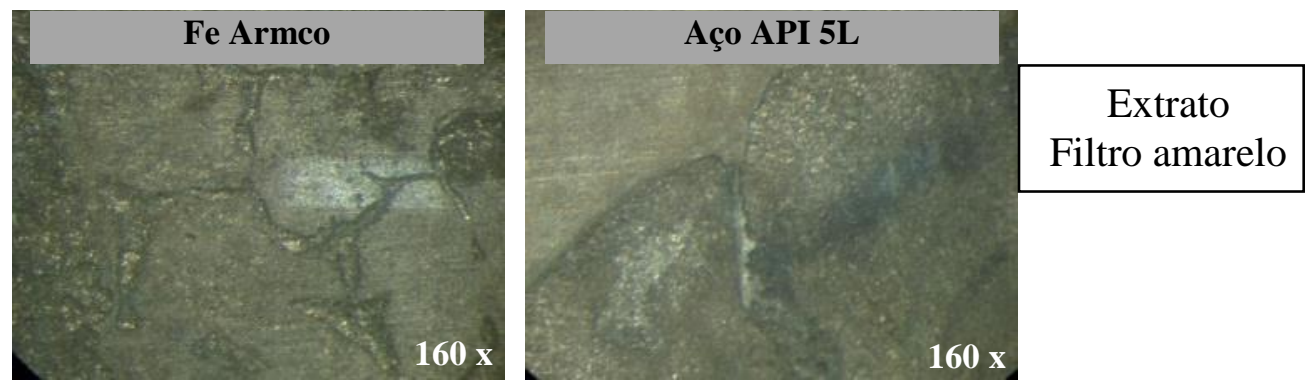

Fonte: As autoras, 2016.

Os valores de taxa de corrosão em (mm/ano) são apresentados na Tabela 2. Os resultados apontaram que para o Fe os extratos não inibiram o processo corrosivo, tendo sido verificada a menor taxa de corrosão em água. No entanto, para o aço, o extrato de filtro amarelo foi o meio com maior caráter inibidor da corrosão, comparativamente.

Tabela 2 - Taxas de corrosão

\begin{tabular}{|c|c|c|}
\hline Solução & $\mathrm{Fe}$ & Aço \\
\hline \hline Lixívia do filtro branco & $9,55 \times 10^{-4}$ & $1,17 \times 10^{-4}$ \\
\hline Lixívia do filtro amarelo & $3,48 \times 10^{-4}$ & $2,16 \times 10^{-5}$ \\
\hline Água destilada & $3,68 \times 10^{-6}$ & $1,42 \times 10^{-3}$ \\
\hline
\end{tabular}

Os resultados obtidos nos testes eletroquímicos indicam o potencial de corrosão medido na interface metal-meio, para cada uma das amostras metálicas nos respectivos meios expostos, apresentados na Tabela 3. Comprovando o maior caráter inibidor para a lixívia do filtro amarelo sobre o aço, comparativamente à lixívia de filtro branco e água destilada. Para o $\mathrm{Fe}$, ambas as lixívias, não representaram a inibição do ataque corrosivo.

Tabela 3 - Potenciais de corrosão $(\mathrm{mV})$ em relação ao ENH.

\begin{tabular}{|c|c|c|}
\hline Solução & Ec Fe & Ec Aço \\
\hline \hline Lixívia do filtro branco & 110 & 200 \\
\hline Lixívia do filtro amarelo & 142 & 155 \\
\hline Água destilada & 70 & 220 \\
\hline
\end{tabular}

Na Figura 8 apresentam-se as voltametrias cíclicas medidas, onde é possível observar que para o Aço a água destilada foi o meio mais agressivo. Quando comparado com os extratos dos filtros, sendo o filtro amarelo o que representou o maior caráter inibidor, com as menores densidades de correntes medidas em um mesmo intervalo de varredura de potencial. Para o Fe observaram-se as menores densidades de correntes para a varredura de potencial realizada, devido a possuir maior resistência a corrosão. Neste caso, foi verificado um comportamento contrário ao aço, ou seja, a água pura foi o meio menos corrosivo dentre os analisados, e os extratos não apresentaram caráter inibidor da corrosão. 
Figura 8 - Voltametrias (a) aço e (b) Fe.
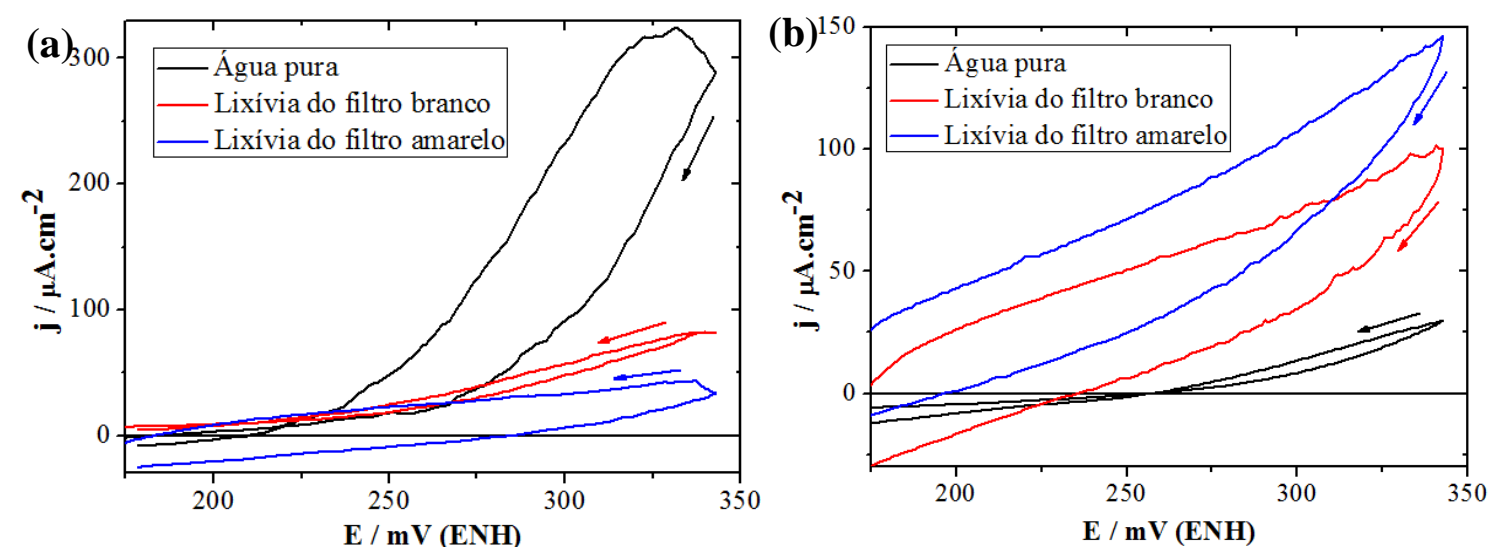

Fonte: As autoras, 2016.

\section{CONCLUSÃO}

Contatou-se a capacidade de inibição da corrosão dos extratos aquo-solúveis, apresentando diferente comportamento frente ao tipo de metal analisado. Na exposição do aço os extratos foram inibidores da corrosão, em relação à água pura. E para o Fe, os extratos promoveram a corrosão, comparando à exposição em água pura, mesmo que o ataque tenha sido considerado leve e superficial. O extrato de filtro amarelo apresentou o maior nível de proteção ao aço, comparando-se com o extrato de filtro branco, o que provavelmente está relacionado aos seus maiores teores de químicos presentes. Este caráter inibidor da corrosão foi confirmado pelos valores de taxa de corrosão, potencial e densidade de corrente observados nos testes eletroquímicos para o aço. Este trabalho comprova a relevância deste estudo, tanto na questão da preservação ambiental, quanto na proteção de materiais, tendo-se alcançado a inibição do ataque corrosivo ao aço, empregando-se um resíduo comum na sociedade.

\section{REFERÊNCIAS}

BRETT, A. M. O.; BRETT, C. M. A., Eletroquímica: Princípios, métodos e aplicações. Coimbra, Portugal: Oxford University Press, 1996.

CARVALHO, V. Saiba como transformar bitucas de cigarro em adubo, bancos de jardim e pequenos objetos, 2014.

GENTIL, V., Corrosão. $6^{\text {a }}$ Edição, Rio de Janeiro: LTC, 2011.

PENNA, C. Bituca de cigarro: uma grande vilã ambiental, 2012.

TONON, F. A. L.; VALENTE, J. G. P.; CAROLO, L. C.; BERALDO, P. N. A utilização de bitucas de cigarro reciclados em projetos de hidrossemeadura. Revista Ciências do Ambiente (online), UNICAMP, 2012.

VAHIDHABANUL, S.; RAMESHBALU, B.; BADU, P. S.; RAHMAN, H. A., Study of cigarette butts extract as corrosiveinhibitiing agent in J55 steel material. International Journal of Research in Engineering and Technology, v.3, n.1,jan. 2014. 